\title{
Thermal Damage Modeling Analysis and Validation during Treatment of Tissue Tumors
}

\author{
Mhamed Nour, Aziz Oukaira, Mohammed Bougataya, and Ahmed Lakhssassi \\ Computer Engineering Department, University of Quebec in Outaouais Gatineau, (PQ), 18X 3X7, Canada \\ Email: \{noum03, ouka02, bouga01, lakhah01\}@uqo.ca
}

\begin{abstract}
The objective of the Laser Interstitial Thermal Therapy (LITT) in treatment is the maximization of the therapeutic effects (tumor tissue laser ablation) with the minimization of any side effects (damage to healthy tissue). The big challenge is the approximation of the tissue tumor topology. While using the MRI stack to capture the 3D tissue tumor topology, a software for conversion to $3 \mathrm{~d}$ stl file can be used, but the result is always far away from the real topology of the tissue tumor. Mathematical models will help us predict the temperature distribution and tissue damage during the dosimetry planning phase. These models need to be validated with real data in order to be accepted and used by physicians in the dosimetry planning. This paper describes a modeling analysis approach for the prediction of laser ablation volume during the planning phase. Three different COMSOL implementations of thermal damage during the Laser Interstitial Thermal Therapy in Treatment of tissue tumors were proposed and validated with real data to confirm the validity of these models. A prediction damage formulation is generated and implemented as a FieldProgrammable Gate Array (FPGA). The final product of these implementations is expected to be used by physician as apps during the planning of the dosimetry. ${ }^{1}$
\end{abstract}

Index Terms-biomedical informatics, computational biology, laser interstitial thermal therapy, laser ablation, dosimetry planning.

\section{INTRODUCTION}

With the integration of Laser Interstitial Thermal Therapy (LITT) with MRI (magnetic thermal imaging) in order to produce MRTI (magnetic resonance thermal imaging) which is now a new option for the cancer treatment, many real case studies in the domain of LITT are published in literature. They differ by the type of tissue used, the specification of the laser source, the power used during the treatment and the time of the treatment.

In this paper, our approach were compared to the real results and confirm the validity of our results to predict thermal damage and temperature distribution during the treatment of tissue tumors.

A valid prediction approach will help improve the health care system and help physicians during the planning phase of the treatment with the objective being the maximization of the therapeutic effects and the minimization of any side effects.

Manuscript received June 25, 2017; revised August 23 , 2017.

\section{LITT AND CASE STUDIES}

LITT uses light absorption to create a precise minimally, invasive injury to targeted tissue inducing acute coagulation necrosis [1]. The Visualize system and Neuroblate system are using the MRI guided technology.

Many real case studies [1-6] in the domain of LITT are published in the literature. They differ by the tissue, the specification of the laser source, the power used during the treatment and the time of the treatment. Let's briefly describe the treatment used by the case studies.

\section{A. Human Brain}

As stated in (1), they used the Visualize system which consists of $15 \mathrm{~W}, 6980 \mathrm{~nm}$ diode, Led of $1.6 \mathrm{~mm}$ diameter, cooling apparatus, and an image-processing workstation. The laser fiber was placed at the center of the lesion in the human brain, then two thermal ablations were performed: 11 watts for 31 second and 10 watts for 30 seconds. Fig. 1 shows the MRI of the brain with the right thalamic enhancing tumor.

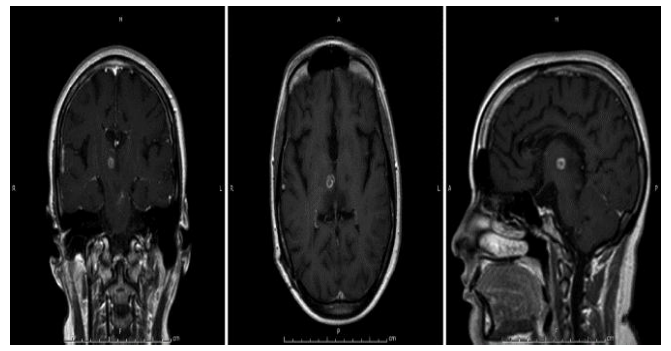

Figure 1. MRI of the brain that show the right thalamic enhancing tumor.

Fig. 2 shows the MRI with damage, as stated in [1] the size of the laser ablation is $2.5 \mathrm{~mm}$ by $9.5 \mathrm{~mm}(23.75$ $\mathrm{mm} 2$ ). Some of the case studies provide their results in $2 \mathrm{D}$ only because it is difficult to calculate the volume from MRI Stack. With our simulation tools, this sytudy validate the 2D dimensions and provide the third dimension.
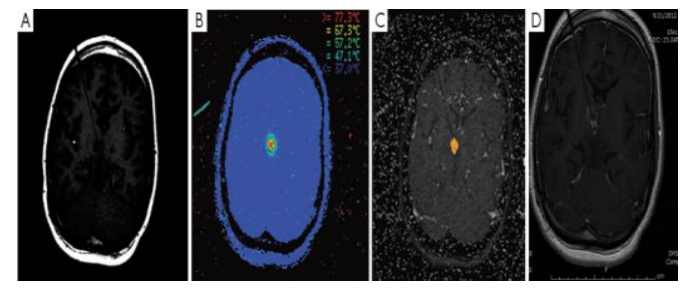

Figure 2. IMRI with the damage model 


\section{B. Animal Tumor Model}

As stated in [2], their ablation system consists of a 15 $\mathrm{W}, 980 \mathrm{~nm}$ diode laser, flexible diffusing tipped fiber optic and 17-gauge internally cooled catheter. Laser ablations were performed using powers of $10 \mathrm{~W}, 12.5 \mathrm{~W}$, and $15 \mathrm{~W}$, during times between 60 and 180 seconds. The results are [2]: When a single applicator was used [2], the great ablation diameters ranged from $12 \mathrm{~mm}$ at the lowest dose $(10 \mathrm{~W}, 60 \mathrm{sec})$ to $26 \mathrm{~mm}$ at the highest dose $(15 \mathrm{~W}$, $180 \mathrm{sec})$. With multiple applicators ablation zones were up to $42 \mathrm{~mm}$ in greatest diameter ( $15 \mathrm{~W}$ for $120 \mathrm{sec})$.

Fig. 3 shows the typical ablation created with a singleapplicator, single-exposure of $15 \mathrm{~W}$ for 120 seconds. The lesion shown (arrowheads) measures $20 \mathrm{~mm} \times 23 \mathrm{~mm}$ in gross dimensions and contained an estimated thermally coagulated volume of $4987 \mathrm{~mm}^{3}$.

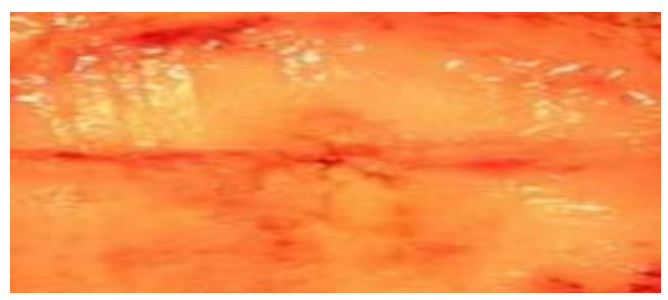

Figure 3. IMRI with the damage model.

\section{Fresh Piece of Porcine Muscle Tissue}

For the fresh piece of porcine muscle tissue ablation process [3], the following settings were used: time of application: $300 \mathrm{~s}$, laser power: $30 \mathrm{~W}$, blood flow rate: 40 $\mathrm{ml} / \mathrm{s}$, and applicator-vessel edge distance: $3 \mathrm{~mm}$.

Fig. 4 shows the damage zone of the experiment. The lesion is about $2 * 1.2 \mathrm{~cm}^{2}$.

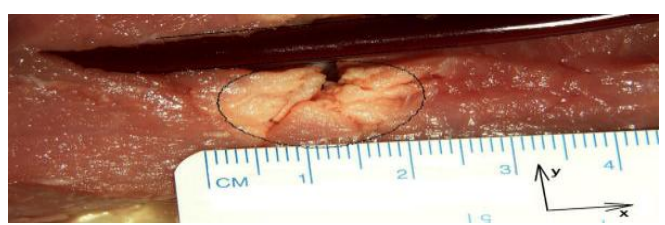

Figure 4. Tissue ablation.

\section{In Vivo Validation of a Therapy Planning System for LITT of Liver Malignancies}

The ablation is increasingly being used for the treatment of liver malignancies [4]. LITT (28 W, $20 \mathrm{~min}$ ) was performed in close contact to major hepatic vessels in six pigs. After explanation of the liver, the coagulation area was documented. The liver and its vascular structures were segmented from a pre-interventional CT scan. Therapy planning was carried out including the cooling effect of adjacent liver vessels. The volume of lesions [4] in vivo was $6,568.3 \pm 3,245.9 \mathrm{~mm}^{3}$.

\section{E. Laser-Induced Thermotheraoy for Lung Tissue Ablation}

Thermal lesions [5] were induced in healthy porcine lungs using an Nd:YAG laser (1,064 nm). LITT was performed with a percutaneous application system in group I $(n=18)$ and an intraoperative application system in group II $(\mathrm{n}=90)$. Laser energy was applied for 600 1,200 seconds in a power range of $20-32 \mathrm{~W}(12,000-$ $38,400 \mathrm{~J}$ ). With the percutaneous puncture system (group $\mathrm{I})$, the application of $28 \mathrm{~W}(16,800 \mathrm{~J})$ for $10 \mathrm{~min}$ generated the largest lesions with a volume of $12.54+/$ $1.33 \mathrm{~cm}^{3}$, an axial diameter of $39.33+/-2.52 \mathrm{~mm}$, and a diametrical diameter of $24.67+/-1.15 \mathrm{~mm}$. The intraoperative application system (group II) achieved the largest lesion volumes of $11.03+/-2.54 \mathrm{~cm}^{3}$ with diameters of $34.6+/-4.22 \mathrm{~mm}$ (axial) and $25.6+/-2.51$ $\mathrm{mm}$ (diametrical) by an exposure time of $20 \mathrm{~min}$ and a power of $32 \mathrm{~W}(38,400 \mathrm{~J})$.

\section{F. Case Study Ex Vivo and in Vivo Evaluation of Laser- Induced Thermotherapy for Nodular Thyroid Disease}

Thermal lesions [6]-[8] were induced in healthy porcine thyroid glands ex vivo $(\mathrm{n}=110)$ and in vivo $(\mathrm{n}=$ 10) using an $\mathrm{Nd}$ :YAG laser $(1,064 \mathrm{~nm})$. Laser energy was applied for 300 seconds with power range of 10-20 W. During the ablation, continuous temperature measurement at a distance of 5 and $10 \mathrm{~mm}$ from the applicator was performed.

The maximum inducible lesion volumes were between $0.74+/-0.18 \mathrm{~cm}^{3}$ at a laser power of $10 \mathrm{~W}$ and $3.80+/-$ $0.41 \mathrm{~cm}^{3}$ at $20 \mathrm{~W}$. The maximum temperatures after ablation were between $72.9+/-2.9$ degrees $C(10 \mathrm{~W})$ and $112.9+/-9.2$ degrees $\mathrm{C}(20 \mathrm{~W})$ at a distance of $5 \mathrm{~mm}$ and between $49.5+/-2.2$ degrees $C(10 \mathrm{~W})$ and $73.2+/-6.7$ degrees $C(20 \mathrm{~W})$ at a distance of $10 \mathrm{~mm}$ from the applicator.

\section{Simulation AND VALIDATION PROCESS}

\section{A. The Simulation Model}

The tissue geometry is represented as a cylinder of $2.54 \mathrm{~cm}$ radius by $2.54 \mathrm{~cm}$ thickness, as shown in Fig. 5 . The tissue is then heated up according the case study. The initial temperature of the tissue will vary with each case study.

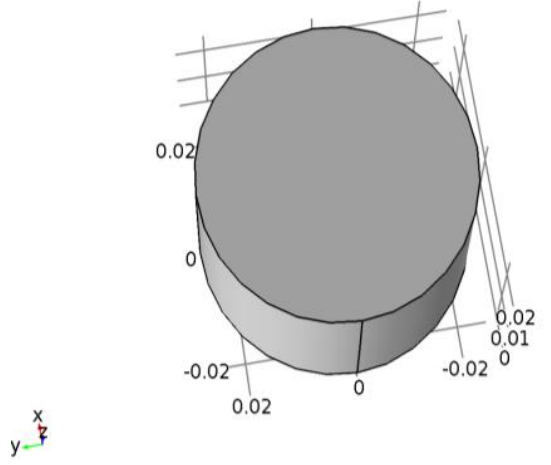

Figure 5. The tissue geometry is represented as a cylinder of $2.54 \mathrm{~cm}$ radius by $2.54 \mathrm{~cm}$ thickness.

\section{B. MRI to STL Conversion Software}

The 3D Slicer software has been used to convert a MRI stack of a brain tumor after completing the steps; the data load, volume, crop volume, editor and save the output as a stl file. The stl file version has been used on 
our COMSOL simulation. Fig. 6 is the result of the transfer of the 3D slicer from the MRI stack to STL.

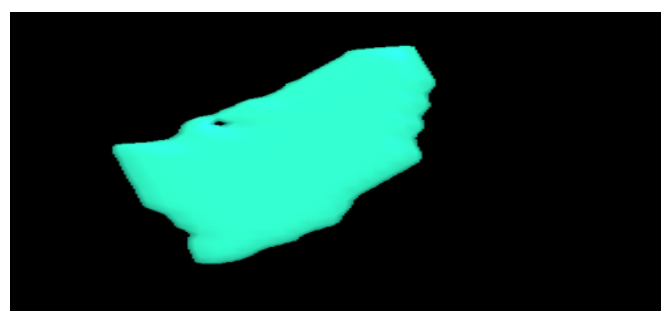

Figure 6. STL file generated from an MRI stack of the tissue tumor of a brain.

STL or Stereo Lithography format, is an engineering file format created by 3D Systems for use with computeraided design (CAD) software.

\section{Conversion Software Limitation}

This study used 3D Slicer, Osirix and others software to convert MRI stacks to STL format. It is really difficult to have an exact tissue tumor geometry because of the manual steps used to select the tissue tumor limits. In general, the geometry received does not reflect the real geometry of the tissue. A new approach for delimitation and calculation of the geometry of the tissue tumor has been proposed.

\section{New Approach for Tumor Geometry Calculation}

Since it is very simple to calculate coordinates and distance between points while using MRI Stacks, the software Osirix has been used to define the limits between healthy and tumor tissues, use these coordinates in the COMSOL software to draw the tumor tissue.

Fig. 7 extract from Osirix Pro [9], [10] shows the 3D coordinates of the limits between healthy and tumor tissues or the Brain. The coordinate's points to define the geometry of the tumor tissue were used to define the tumor edges.

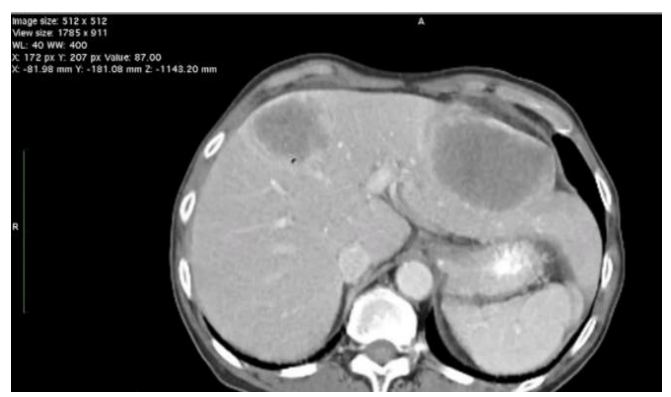

Figure 7. Tumor limit coordinates in 3D.

\section{E. Heat Distribution}

Our model is using the bio heat transfer with time dependent study. The Heat Equation used for this simulation.

$$
\begin{gathered}
\rho C_{p} \frac{\partial T}{\partial t}+\rho C_{p} \mathrm{u} \cdot \nabla T+\nabla \mathrm{q}=Q+Q_{\text {bio }} \\
\mathrm{q}=-\kappa \nabla \mathrm{T}
\end{gathered}
$$

$$
Q_{\text {bio }}=>\rho_{b} C_{b} \omega_{b}\left(\mathrm{~T}_{b}-\mathrm{T}\right)+Q_{m e t}
$$

Where $\mathrm{Cp}$ is the heat capacity $\mathrm{J} /(\mathrm{kg} * \mathrm{~K})), \rho$ is the density of the brain tissue $\left(\mathrm{kg} / \mathrm{m}^{\wedge} 3\right)$, $\mathrm{T}$ is temperature $(\mathrm{K}), \mathrm{k}$ is the thermal conductivity of the brain tissue $((\mathrm{W} /(\mathrm{m} * \mathrm{~K}))$, and $\mathrm{C}_{\mathrm{p}}$ is the heat capacity $\left.\mathrm{J} /(\mathrm{kg} * \mathrm{~K})\right), \mathrm{Q}$ is the laser source, $\mathrm{q}$ is the heat flux density, $\mathrm{Q}_{\mathrm{bio}}$ represents the perfusion, $\mathrm{C}_{\mathrm{p}}$, $\mathrm{w}_{\mathrm{b}}, \mathrm{T}, \mathrm{t}, \rho_{\mathrm{b}}, \mathrm{Q}_{\mathrm{met}}, \mathrm{Tb}$ are respectively specific blood heat, blood perfusion rate, temperature, time, blood density, metabolic heat source, blood flow rate.

\section{F. Modeling of the Laser Source}

Three formulations were used to model the laser power source. Each one will have a specific definition and properties. This study applied the entire model to all these case studies, compare the results of their simulations. Select the best formulation that approximate the experimentation and come with an implantation that can be used by the physician to predict the damage volume.

\section{G. Laser Heat Flux Function of Laser Power}

The laser heat source [11]-[13] is assumed to have a Gaussian distribution with a maximum heat flux at the laser beam spot center. The laser heat flux is a function of the laser power, the laser beam spot radius and the radial distance from the laser beam spot center, as shown in Equation (4).

$$
\mathrm{q}=\frac{2 \mathrm{p}}{\pi \mathrm{r}_{\mathrm{b}}^{2}} \mathrm{e}^{-2 \mathrm{r}^{2} / r_{b}^{2}}
$$

Where $\mathrm{q}$ is the laser heat flux, $\mathrm{P}$ is the laser power, $\mathrm{r}_{\mathrm{b}}$ is the radius of the laser beam spot at the work piece surface, and $r$ is the radial distance from the laser beam spot center.

\section{H. The Incident Laser Power is Distributed in Time and Space with A Gaussian Shape}

The heat source term can be written as follows (8).

$$
Q=(1-\mathrm{R}(\mathrm{T})) \alpha(T) P_{i n}(\chi, \mathrm{t}) \mathrm{I}(\mathrm{y})
$$

Where $\alpha(T)$ is the material absorption coefficient, $R(T)$ the surface reflectivity, Pin the incident laser power and $\mathrm{I}(\mathrm{y})$ the relative intensity given by the Beer-Lambert law.

$$
\mathrm{I}(\mathrm{y})=\exp y(-\alpha(t)|y|)
$$

The incident laser power is distributed in time and space with a Gaussian shape.

$$
\mathrm{P}(\chi, \mathrm{t})=P_{0} \exp \left\{-\left(\frac{\mathrm{t}-\mathrm{t}_{0}}{\frac{\tau}{2}}\right)^{2}\right\} \exp \left\{\left(-\left(\frac{\chi}{r}\right)^{2}\right\}\right.
$$

Where $\mathrm{P}_{0}$ is the peak power of the laser beam, $\mathrm{t}_{0}$ the time shift, $\tau$ the pulse time, $r$ the beam radius at half height.

The absorption coefficient $\alpha(\mathrm{T})$ and the reflectivity $\mathrm{R}(\mathrm{T})$ can be calculated from the complex refractive index $\mathrm{n}-\mathrm{ik}$. 


$$
\begin{gathered}
\alpha(T)=\frac{4 \pi k(T)}{\lambda} \\
R(T)=\frac{(n(T)-1)^{2}+k(T)^{2}}{(n(T)+1)^{2}+k(T)^{2}}
\end{gathered}
$$

Where $\lambda$ is laser wavelength.

\section{Electromagnetic heat source}

Electromagnetic waves can be used as a heat source in the form of maser and laser. A maser "microwave amplification by stimulated emission of radiation") is a device that produces coherent electromagnetic waves through amplification by stimulated emission (1). Modern masers can be designed to generate electromagnetic waves at not only microwave frequencies but also radio and infrared frequencies. The laser "light amplification by stimulated emission of radiation" works by the same principle as the maser, but produces higher frequency coherent radiation at visible wavelengths (1). Laser and microwave works at different wavelengths, and can be used as heat sources depending on the nature of the application. The external heat source is equal to the resistive heat generated by the electromagnetic field (2).

$$
\begin{gathered}
Q=\frac{1}{2} \mathrm{R}_{\mathrm{e}}\left[(\sigma-\mathrm{j} \omega \mathrm{t}) \mathrm{E} \cdot \mathrm{E}^{\bullet}\right] \\
\mathrm{E}=e_{r} \frac{c}{r} e^{j(\omega t-\mathrm{kz})}
\end{gathered}
$$

Where $\mathrm{E}$ is the electric field intensity, $\mathrm{r}$ is radius, $\mathrm{z}$ is direction, $\mathrm{c}$ is speed of light, $\mathrm{k}$ of is the wave number, $\sigma$ is conductivity, $\omega$ is frequency in radians, $\varepsilon$ is permittivity, $\mathrm{j}$ represents imaginary part.

\section{J. Thermal and Optical Properties}

Thermal and optical properties of the tissue vary with the temperature. Linear equations were used which employ constant temperature coefficients for these thermal and optical properties. The temperature dependence of the thermal conductivity and density is taken into consideration by the following linear approximations (12).

$$
\begin{gathered}
\mathrm{K}(\mathrm{T})=k_{\left(37^{c c}\right)}(1+0.00025(T-37)) \\
\mathrm{P}(\mathrm{T})=k_{\left(37^{c c}\right)}(1+0.00025(T-37))
\end{gathered}
$$

\section{K. Definition of the Thermal Damage}

The first order Arrhenius equation were used to compute the damage integral (13).

$$
\Omega(\mathrm{t})=\ln \frac{c_{0}}{c_{U D}(t)}=\int A \exp \left[-\frac{\mathrm{E}_{\mathrm{a}}}{\mathrm{RT}(\mathrm{t})}\right]_{d t}
$$

Where $\mathrm{C}_{0}$ is the original concentration of undamaged cells, $\mathrm{C}_{\mathrm{UD}}$ is the concentration of the remaining living cells after time $\mathrm{t}$, the treatment time, $\mathrm{A}$ is the frequency factor, $E_{a}$ is the activation energy and $R$ is the universal gas constant. $\left(\mathrm{R}=8.314 \mathrm{~J} \mathrm{~mol}^{-1} \mathrm{~K}^{-1}\right)$.

\section{Results of the Simulation}

Table I shows the description of the parameters during the experimentation such as wavelength, laser power, radius of laser spot and time for each case study. It also shows the result of the experimentations in term of damage surface or damage volume for each implementation.

\section{Laser Heat Flux}

The results of this simulation are very different from the real data of the case studies, because the laser formulation does not take into account a lot of parameters in comparison to the electromagnetic field.

\section{N. The incident Laser Power}

The results of this simulation are also very different from the real data from the case studies, because the laser formulation is not adequate for human tissue ablation.

\begin{tabular}{|c|c|c|c|}
\hline Cases & $\begin{array}{l}\text { Result. Laser } \\
\text { Heat Flux. }\end{array}$ & $\begin{array}{l}\text { Result. The } \\
\text { incident } \\
\text { laser power }\end{array}$ & $\begin{array}{l}\text { Result. } \\
\text { Electromagnetic }\end{array}$ \\
\hline $\begin{array}{l}\text { Litt Human } \\
\text { Brain }\end{array}$ & $\begin{array}{c}455.13 \mathrm{~mm} 3 \\
2.5 \times 9.5 \times 19.16 \\
\mathrm{~mm}^{3}\end{array}$ & $1800 \mathrm{~mm}^{3}$ & $\begin{array}{c}441.3 \mathrm{~mm}^{2} \\
\mathrm{Z}=18.58 \mathrm{~mm}\end{array}$ \\
\hline $\begin{array}{c}\text { Animal Tumor } \\
\text { Model }\end{array}$ & $597.06 \mathrm{~mm}^{3}$ & $630 \mathrm{~mm}^{3}$ & $1636.6 \mathrm{~mm}^{3}$ \\
\hline $\begin{array}{c}\text { Fresh piece of } \\
\text { muscle }\end{array}$ & $\begin{array}{c}0.91273 \mathrm{~cm}^{3} \\
2 \times 1.2 \times 0.38 \mathrm{~cm}^{3}\end{array}$ & $24622 \mathrm{~mm}^{3}$ & $0.98020 \mathrm{~mm}^{3}$ \\
\hline $\begin{array}{c}\text { Litt Liver } \\
\text { malignancies }\end{array}$ & $877.97 \mathrm{~mm}^{3}$ & $42020 \mathrm{~mm}^{3}$ & $1096.6 \mathrm{~mm}^{3}$ \\
\hline $\begin{array}{c}\text { Litt Lung } \\
\text { Tissu } \\
\text { (29w-10min) }\end{array}$ & $5320 \mathrm{~mm}^{3}$ & $7353 \mathrm{~mm}^{3}$ & $11.417 \mathrm{~cm}^{3}$ \\
\hline $\begin{array}{c}\text { Litt Lung } \\
\text { Tissu } \\
\text { (32W-20min) }\end{array}$ & $4820 \mathrm{~mm}^{3}$ & $67232 \mathrm{~mm}^{3}$ & $13.383 \mathrm{~cm}^{3}$ \\
\hline $\begin{array}{l}\text { LiTT Thyrois } \\
\text { disease } \\
(10 \mathrm{~W}-300 \text { sec })\end{array}$ & $1500 \mathrm{~mm}^{3}$ & $16415 \mathrm{~mm}^{3}$ & $\begin{array}{c}2.56 \mathrm{~cm}^{3} \\
\text { at applicator @ } 0 \mathrm{~mm} \\
1.9 \mathrm{~cm}^{3} \\
\text { at applicator @ } 5 \mathrm{~mm} . \\
1.45 \mathrm{~cm}^{3} \\
\text { at applicator@ } 10 \mathrm{~mm}\end{array}$ \\
\hline $\begin{array}{c}\text { LITT Thyrois } \\
\text { disease } \\
(20 \mathrm{~W}-300 \mathrm{sec})\end{array}$ & $2120 \mathrm{~mm}^{3}$ & $32830 \mathrm{~mm}^{3}$ & $\begin{array}{c}4 \mathrm{~cm}^{3} \\
\text { at applicator @ } 95 \mathrm{~mm} \\
2.9 \mathrm{~cm}^{3} \\
\text { at applicator @ } 10 \mathrm{~mm}\end{array}$ \\
\hline
\end{tabular}

\section{O. Electromangnetic Laser Power}

The results of this simulation are good for LITT when using the specification described for laser specification, especially for LITT lung and thyroid tissues.

This formulation were used for the rest of our studies.

TABLE I. VOLUME DAMAGE FormULATION FOR EACH SiMULATION

From the data generated during our simulation with laser defined as electromagnetic field, and for the wavelength equal to $1064 \mathrm{~nm}$, a prediction formulation was generated with input power and time, and output the damage volume. This prediction formula Table II can be used by the physician during the laser ablation process. Fig. 9-12 represent the graphs of these formulations. Fig. 
8 shows the Simulink Matlab function representing the volume damage as output and power, time as inputs.

\begin{tabular}{ccc} 
TABLE II. & $\begin{array}{c}\text { Volume Damage FoRmulation FOR EACH POWER } \\
\text { VALUE }\end{array}$ \\
\hline \hline POWER & EQUATION & $\boldsymbol{R}^{\mathbf{2}}$ \\
\hline $\mathbf{1 0} \mathbf{W}$ & $\mathrm{v}=-2 \mathrm{E}-0.5 \mathrm{t}^{\wedge} 2+0.0135 \mathrm{t}+0.002$ & 0.99 \\
$\mathbf{2 0} \mathbf{W}$ & $\mathrm{v}=-2 \mathrm{E}-0.5 \mathrm{t}^{\wedge} 2+0.0134 \mathrm{t}+0.0044$ & 0.99 \\
$\mathbf{2 8} \mathbf{W}$ & $\mathrm{v}=-2 \mathrm{E}-05 \mathrm{t}^{\wedge} 2+0.0325 \mathrm{t}-0.1281$ & 0.99 \\
$\mathbf{3 2} \mathbf{W}$ & $\mathrm{v}=-2 \mathrm{E}-05 \mathrm{t}^{\wedge} 2+0.0295 \mathrm{t}-0.0905$ & 0.99 \\
\hline \hline
\end{tabular}

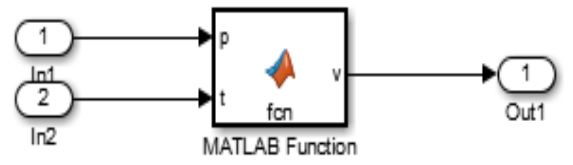

Figure 8. Simulink matlab function of the volume damage.

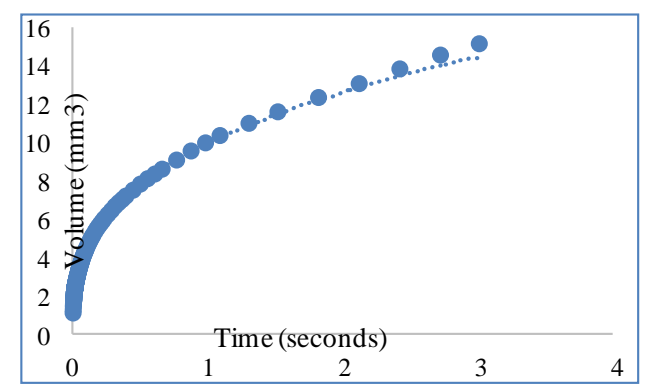

Figure 9. Volume graph with power at $10 \mathrm{~W}$.

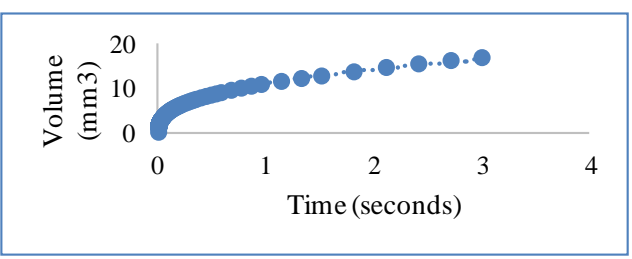

Figure 10. Volume graph with power at $20 \mathrm{~W}$.

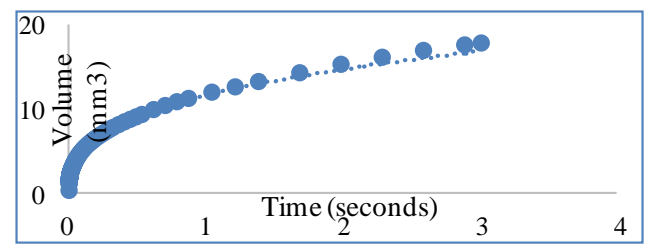

Figure 11. Volume graph with power at $28 \mathrm{~W}$.

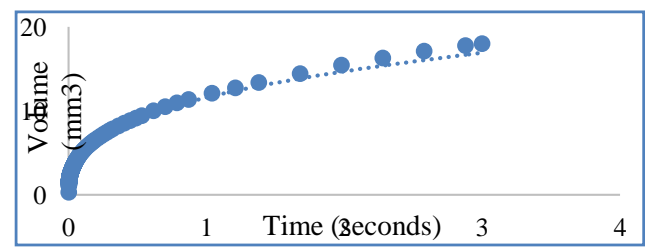

Figure 12. Volume graph with Power at $32 \mathrm{~W}$.

Table III shows the radius of the sphere generated by the laser ablation, and correspond to the damage volume calculated by the experimentation.
TABLE III. RADIUS OF THE SPHERE FOR POWER $=20 \mathrm{~W}$

\begin{tabular}{ccccc}
\hline \hline Power $[$ W & Time $[\mathrm{s}]$ & $\begin{array}{c}\text { D Volume } \\
{\left[\mathbf{m m}^{3}\right]}\end{array}$ & $\begin{array}{c}\text { Radius- } \\
\text { sphere }\end{array}$ & Cube - edge \\
\hline $\mathbf{2 0}$ & 15 & 0.19131 & 0.357511291 & 0.576207921 \\
$\mathbf{2 0}$ & 30 & 0.38503 & 0.451379739 & 0.72749753 \\
$\mathbf{2 0}$ & 45 & 0.57446 & 0.515779175 & 0.831291356 \\
$\mathbf{2 0}$ & 60 & 0.75578 & 0.565165535 & 0.910888317 \\
$\mathbf{2 0}$ & 75 & 0.92171 & 0.603821591 & 0.973191035 \\
\hline \hline
\end{tabular}

\section{EXPERIMENTAL IMPLEMENTATION AND RESULTS}

The main purpose of this section is the implementation and validation of the theoretical results and volume simulation. The VHDL code will be put into the operation designed to facilitate the development of the architecture for their implementation in VLSI [14]-[17]. This architecture will be modeled in a high-level language and simulated to assess its performance and implemented on an FPGA. Model validation of the simulation results is made using the software Modelsim under Quartus Prime, which allows us to simulate the behavior of the system in time. Our design flow will be divided into three main parts: simulation, synthesis, and implementation of VHDL code development. A description of each part will be presented.

\section{A. Creation and Simulation VHDL Code}

In this part, a design a volume module with VHDL code editor will be presented. A stimuli will be created with the help of the editor and use these stimuli to simulate the operation of the code theory on cible. This Fig.13 shows the top-level module of our volume module.

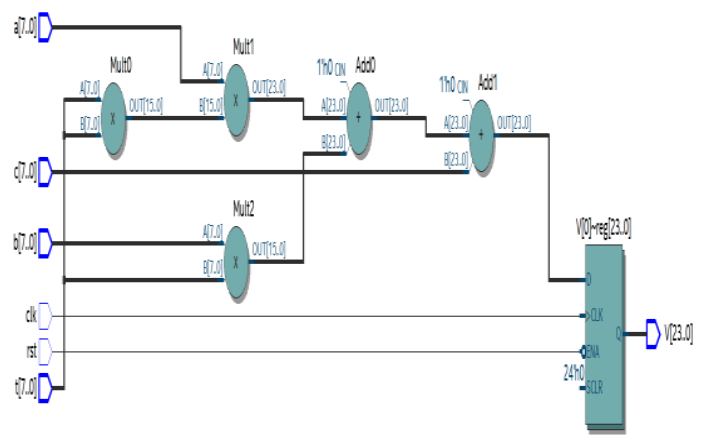

Figure 13. Top level of the volume module.

After generating the two .vhd files (the primary file system and the bench to "Test Bench" test) with the "System Generator" comes the role of the Quartus Prime Navigator that will synthesize the design to generate the RTL files. Now that the board must be specified, a highperformance DE1 card were chosen that is widely used in industry, the Altera FPGA board of DE1 cyclone $\mathrm{V}$ as family and the 5CSEMA5F31C6 as a device as is shown in Fig. 13. 


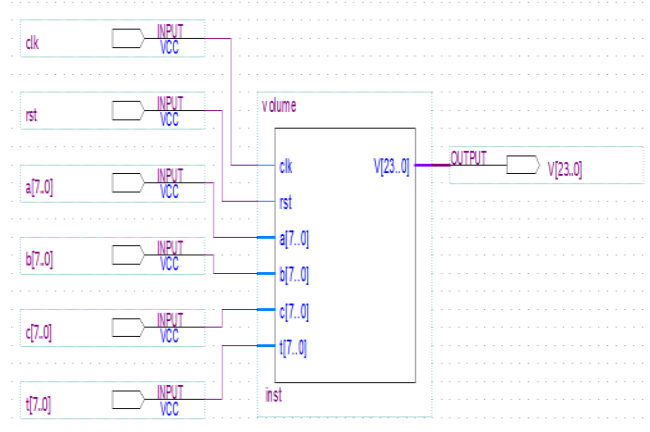

Figure 14. Structure of the volume module in quartus prime.

The structure of the volume module after synthesis with Quartus Prime from Altera shows the way to calculate the volume $\mathrm{V}$, intermediate values of the following parameters were used: $a, b, c$ and t. The VHDL code implanted was validated against the study before based on the theoretical analysis and finite element method (FEM). The around volume values increased as shown by the results of the comparison show the following Fig. 14.

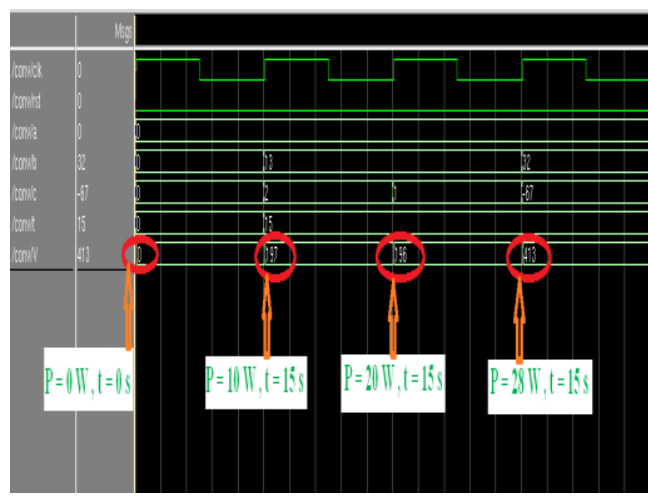

Figure 15. Display results of simulation the VHDL code.

The VHDL code was validated against the study before based on the theoretical analysis and finite element method (FEM) with COMSOL tool. Practically even volume values increased as shown by the results of the comparison show the following Fig. 15. As part of this paper, a simulation and synthesis of an equation of volume and its advantage through the VHDL code were developed here at the laboratory LIMA and a 'test bench' that is to verify the ability of our algorithm to operate per the initial specifications were also developed. Then created test vectors to ensure a specific fault coverage optimizing the time of the test or minimizing the following performance degradation and Fig.15 summarizes the volume results at $0 \mu \mathrm{m}^{3}, 197 \mu \mathrm{m}^{3}, 196$ $\mu \mathrm{m}^{3}$ and $413 \mu \mathrm{m}^{3}$.

\section{B. Implementation and Download the VHDL Code on DE1}

Once compiled after the assignment of the pins, our program is ready to be downloaded on the card DE1 cyclone $\mathrm{V}$ as family and 5CSEMA5F31C6 as device and the code to be downloaded successfully on the card. Right now, our program is rolling and should produce outputs. The clock is at $50 \mathrm{MHz}$, so the outputs should change with a frequency of $50 \mathrm{MHz}$ and the following Fig. 15 shows the last value $\left(413 \mu \mathrm{m}^{3}\right)$ at 15 second to implement on LCD the reader without floating point.

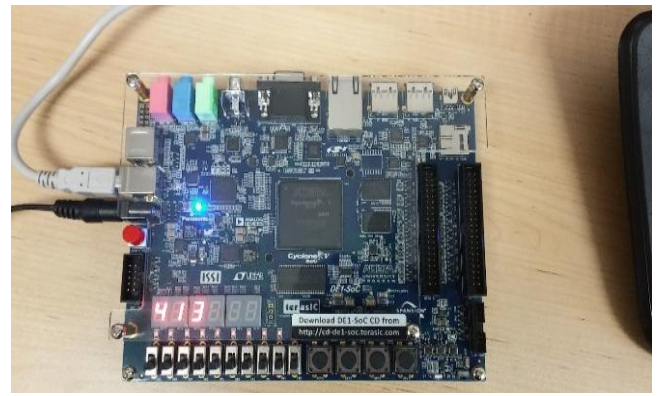

Figure 16. The code value and implement on DE1 Altera cyclone.

This simulation and implementation of volume using FPGA applied in any kind of environment to get improved performance with respect to the conventional scheme (Fig. 16), also able to keep the temperature constant at the desired value regardless of changes in the load or the environment. Thus, the overshooting problem can be solved up to a great extent.

\section{CONCLUSION}

In this paper, an approach for volume damage analysis and a validation of its effectiveness were proposed. Also proposed an approach for delimitating the healthy and tumor tissues. The new geometry with thermal switches were used and three mathematical formulations of the laser ablation sources were compared to real cases and used the best one to predict the volume damage.

The results were used to help physicians to predict the volume damage during laser ablation planning. Next step will be a proposition for an automatic procedure for the LITT.

\section{REFERENCES}

[1] M. Riordan and Z. Tovar-Spinoza, "Laser induced thermal therapy (LITT) for pediatric brain tumors: Case-based review," Transactional Pediatrics, vol. 3, pp. 229-235, 2014.

[2] K. Ahrar, et al., "Preclinical assessment of a 980-nm diode laser ablation system in a large animal tumor model," Journal of Vascular and Interventional Radiology, vol. 21, no. 4, pp. 555-561, 2010.

[3] Y. Mohammed and J. F. Verhey, "A finite element method model to simulate laser interstitial thermo therapy in anatomical inhomogeneous regions," Biomedical engineering online, vol. 4, no. 1, p. 2, 2005.

[4] K. S. Lehmann, et al., "In vivo validation of a therapy planning system for laser-induced thermotherapy (LITT) of liver malignancies," International Journal of Colorectal Disease, vol. 26, no. 6, p. 799, 2011.

[5] J. P. Ritz, et al., "Laser-induced thermotherapy for lung tissue evaluation of two different internally cooled application systems for clinical use," Lasers in Medical Science, vol. 23, no. 2, pp. 195-202, 2008.

[6] J. P. Ritz, et al., "Ex vivo and in vivo evaluation of laser-induced thermotherapy for nodular thyroid disease," Lasers in Surgery and Medicine, vol. 41, no. 7, pp. 479-486, 2009.

[7] M. Nour, A. Oukaira, M. Bougataya, , and A. Lakhssassi, "Using virtual bang-bang controllers to optimize treatment of brain tumors," ICAR Bahrein, vol. 1, no. 6, pp. 173-182, 2017.

[8] M. Nour, A. Lakhssassi, E. Kengne, and M. Bougataya, "3D simulation of the laser interstitial thermal therapy in treatment 
(LITT) of brain tumors," in Proceeding of the COMSOL Conference, Boston, 2015, pp. 1-6.

[9] A. Oukaira, A. Lakhssassi, R. Fontaine, and R. Lecomte, "Thermal model development for LabPET II scanner adapter board detector module", in Proceeding of the COMSOL Conference, Boston, 2014, pp. 1-5.

[10] O. Abdulghani, et al., "Modeling and simulation of laser assisted turning of hard steels," Modeling and Numerical Simulation of Material Science, vol. 3, no. 4, pp. 106-113, 2013.

[11] C. Rossmann and D. Haemmerich, "Review of temperature dependence of thermal properties, dielectric properties, and perfusion of biological tissues at hyperthermic and ablation temperatures," Critical Reviews ${ }^{\mathrm{TM}}$ in Biomedical Engineering, vol. 42, no. 6, pp. 467-492, 2014.

[12] M. N. Iizuka, et al., "The effects of dynamic optical properties during interstitial laser photocoagulation," Physics in Medicine and Biology, vol. 45, no. 5, p. 1335, 2000.

[13] S. Fujita, M. Tamazawa, and K. Kuroda, "Effects of blood perfusion rate on the optimization of RF-capacitive hyperthermia," IEEE Transactions on Biomedical Engineering, vol. 45, no. 9, pp. 1182-1186, 1998.

[14] A. Oukaira, N. Pal, O. Ettahri, E. Kengne, and A. Lakhssassi, "Simulation and FPGA implementation of thermal convection equation for complex system design", International Journal on Engineering Applications, vol. 4, no. 6, 2016.

[15] A. Oukaira, O. Ettahri, and A. Lakhssassi, "Modeling and FPGA implementation of a thermal peak detection unit for complex system design", International Journal of Advanced Computer Science and Applications, vol. 8, no. 6, pp. 307-312, 2017.

[16] M. Nour, M. Bougataya, and A. Lakhssassi, "Modeling the laser thermal therapy in treatment of brain tumors," in Proceeding of ICECS, Toronto, 2016.

[17] M. Nour, M. Bougataya, K. El Guemhioui, and A. Lakhssassi, "Optimization of the laser cancer treatment planning and thermal dosimetry control," International Journal of Bioscience, Biochemistry and Bioinformatics, vol. 7, no. 1, pp. 1-12, 2017.

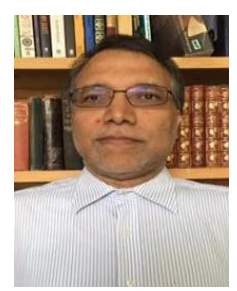

Mhamed Nour received a B. Ing. in Computer Science from INSAE, Rabat, Morocco in 1984, and a M. Sc. A in Computer Science in Software Engineering from Université du Montrèal (UdeM) Québec, Canada in 1994. He also did research on the distributed algorithms for multi-media routing with QoS constraints at CRIM (Centre de Recherche Informatique de Montreal) and UdeM. $\mathrm{He}$ is currently a PhD Student at Université du Québecen Outaouis (UQO), Québec, Canada. Mhamed taught Computer Science for more than 20 years and has been working as a Senior Network Analyst since 1996. His research activities focus on the heat transfer mechanisms in biological tissues for thermal treatment practices and the development of algorithms for automatic bio dosimetry for tumor laser treatment. Mhamed is a member of ReSMiQ and IEEE.

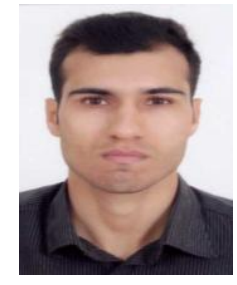

Aziz Oukairareceived a B.Ing. in Computer Science from FS, Casablanca, Morocco in 2008, and M. Sc. A in Computer Science in Software Engineering from FST, Limoges, France in 2010. He also did research on the simulation and design of thermal electronics systems in low frequency and high frequencies in more advanced technologies like $0.18 \mathrm{um}, 65 \mathrm{~nm}, 45 \mathrm{~nm}$, and $28 \mathrm{~nm}$. $\mathrm{He}$ is currently a Ph.D. Student at Université du Québecen Outaouais (UQO), Québec, Canada. Aziz taught Computer Science for more than 7 years. His research activities focus on the heat transfer mechanisms in system complex for thermal treatment practices and development and design of thermal models for complex systems with advanced technologies.

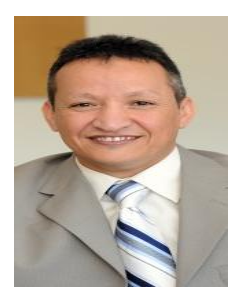

Prof. Dr. Mohmmed Bougataya received the B.Ing. in electrical engineering from USTO University, Oran, Algeria in 1998. He also received the M.Sc.A . and nd Ph.D. in electrical engineering from Université du Québec (UQTR) Québec, Canada in 2003 and 2010 respectively. Mohammed worked as associate Professor of Electrical Engineering at Department of Computer Science and Engineering at the University of Quebec in CANADA since 2012 with interests in heat transfer mechanisms in biological tissues for thermal treatment practices, Thermal Mechanical Stress in Electronic Packaging and Rapid Prototyping for Electronic Systems. His research contributions have been acknowledged by the scientific community and been used to write patent applications. He also has a considerable industrial R \& D experience between 2000 and 2010 with Hyperchip Inc and DreamWafer design group at Techno Cap Inc. Dr Bougataya is the author/co-author of more than 80 scientific publications and research report.

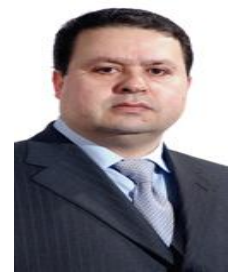

Prof. Dr Ahmed Lakhssassi received the B.Ing. and M.Sc.A in electrical engineering from Université du Québec (UQTR), Québec, Canada in 1988 and 1990 respectively. He also received the Ph.D. in Energy and Material sciences in 1995 from INRS-Énergie et Matériaux Monteal, Québec, Canada. A year also, he had become a professor of Electro-thermo-mechanical aspects at NSERC -Hydro-Quebec Industrial Research Chair at Electrical Engineering Department of the UQTR. Since 1998, he has been with UQO (Université du Québec en Outaouais), where he is currently titular professor and responsible of the LIMA laboratory LIMA (Advanced Microsystem Engineering Laboratory) developing algorithms for Microsystems thermo-mechanical monitoring and associated distributed sensors network. His research activities focus on the development of embedded algorithms for bio-implantable Microsystems, heat transfer mechanisms in biological tissues for thermal treatment practices. He is the author/co-author of more than 150 scientific publications and research report, and thesis advisor of 60 graduate and undergraduate students who completed their studies. Professeur Lakhssassi is a member of ReSMiQ, Nano-Québec, IEEE and OIQ. 